\title{
Assimilation among First-Generation Chinese Immigrants in 2010s: Not Adapting, but Assimilating
}

\author{
Author's Name: Yang Lu
}

University High School

\begin{abstract}
Existing research on the assimilation process between racial/ethnic groups in the United States highlights different gender may behave differently during the process of assimilation. This study engages this previous literature. It draws from based on 30 semi-structured interviews with students at University High School, a public high school in Irvine, California, examining gender differences Chinese immigrants face during US assimilation. But the study shows the assimilation of these participants is not apparent. Assimilation is mutual. These young Chinese immigrants have undergone some educational assimilation in China through their participation in international schools. Additionally, because Irvine has a large number of Chinese immigrants, which means Irvine already has a Chinese social circle, participants can adapt to American by integrating into the existing Chinese social circle. The participants lived in the United States for about three to four years, considered as a short period, which also explains why they did not assimilate.
\end{abstract}

Keywords: Gender, Assimilation, Chinese Immigrant, First generation immigrant, Null finding 